\title{
Impact of Internship Program on Engineering and Technology Education in Ethiopia: Employers' Perspective
}

\author{
Sisay Geremew Gebeyehu (Corresponding Author) \\ Assistant Professor, Faculty of Mechanical and Industrial Engineering \\ Bahir Dar Institute of Technology, Bahir Dar University P.O.Box 26,Bahir Dar, Ethiopia \\ Email: sisayg78@gmail.com
}

\author{
Eshetie Berhan Atanaw \\ Associate Professor, School of Mechanical and Industrial Engineering \\ Addis Ababa Institute of Technology, Addis Ababa University \\ P.O.Box 389, Addis Ababa, Ethiopia \\ Email: berhan.eshetie@gmail.com
}

Received: April 4, 2018

doi:10.5296/jet.v5i2.12945
Accepted: April 16, 2018

Published: August 14, 2018

URL: http://dx.doi.org/10.5296/jet.v5i2.12945

\begin{abstract}
Since the introduction of the ETIP in 2009 in Ethiopia, every year all engineering and technology colleges and faculties run an internship program for a period of four months. As a result, considerable amount of effort and resources are being invested while its impact on the quality of the engineering and technology education is not yet evaluated. The aim of this paper is therefore, to present the impact of the mandatory Engineering and Technology Internship Program (ETIP) in views the employer's perspective based on a nationwide assessment study. Primary data was collected from different sector employers using a standard survey questionnaire. Sample size is determined by using general sample size formula with $5 \%$ significant level or $95 \%$ confidence interval. In the study, from a sample of 103 different sector industries 182 individuals of different in various positions were selected.The major findings of the survey revealed that the length of internship period and working hours in the industry, appropriate supervision and mentorship and provision of appropriate resource during internship as the top influencing factors for internship program to bring the intended impact on the technology and engineering education in Ethiopia. Despite the various advantages inherent in internship programs, the study reveals that undergraduate students internship program still faces lots of challenges including lack of strict placement
\end{abstract}


procedures, limitation of academic mentorship, poor supervisory practice in the industry, and variations in learning facilities both at universities and in the company.Finally, the study concludes that to improve the quality of the present internship education program and to insure its future sustainability, institutional linkages between the universities and host organizations is the number one priority.

Keywords: Engineering, Education, Impact, Internship, Employer

\section{Introduction}

Engineering and Technology Education Internship Program (ETEIP) is a structured educational approach which integrates class room learning with productive, structured work experience(s) that are directly related to the goals and objectives of the engineering and technology education programs in Ethiopia. In order to integrate on-the-job practical field experience with academic studies, internship programs offer students a chance to extend the classroom into a workplace setting. Moreover, ETEIP is also an opportunity to the employer to consider students as prospective employee and evaluate theirskills such as communication, quantitative analysis, information technology, problem-solving and ability to work with other people. In General, the purpose of internship experiences can be explained in some of the following major objectives as (Remaud 2010, Wienhausen and Arzberger 2010) stated:

- To assure a certain awareness and openness of the students to the professional world, particularly to the societal, ethical and human aspects

- To become acquainted with organizations and organizational structures

- To be able to acquire some basic professional reflexes and relational skills and understand their future role within the organization

- To apply a combination of knowledge, capacities and attitudes learnt along the engineering curriculum to a real professional situation

- Ability to design and implement engineering and technology tools and techniques

- Ability to undertake research and to progress to higher levels of studies

Moreover, to fulfil employer's requirements, universities with engineering and technology undergraduate programs have been using internships as a means of providing their students with practical skills/experiences and preparing them for their future careers. On the other hand, hosting organizations will also get the opportunity to nurture and evaluate their prospect/potential employee at a minimum cost and risk. The outcomes of an effective internship program, however, should not be limited to providing and/or enhancing students' skills. To this effect, various researchers have argued that internship programs are beneficial to the trio involved in the programs that is, the students, the universities, as well as the host organizations (Abu et. al, 2011; Cook et al, 2004). As a result, internship programs have gained globally the attention of many tertiary institutions.

In Ethiopia, engineering and technology tertiary education programs have incorporated internship programs which entail attaching students to various organizations so that they can 
have a practical insight on what they have learnt theoretically at school. Since 2009, ETEIP is mandatory for all students in engineering and technology undergraduate degree specializations.Each year allengineering and technology colleges and faculties run an internship program for a period of four months (one semester with equivalent up to 30 ECTS (European Credit Transfer System)) during the academic calendar at their fourth and fifth year. While a student is on internship, a faculty supervisor/mentor, is assigned to regularly follow up and visit the student at least once during his/her internship time. In addition, each host organization assigns a factory supervisor for each student to advise and assist their day to day activities.

Each year an estimated amount of over half a billion ${ }^{1}$ is being spent from government budget to run the program. Even though, the industrial sector believes that development of internship programs is an important issue for enhancing technical and soft skills of students who are the future workforce, there are still challenges that both the students and the industry are now experiencing. Since most of the tertiary institutions in Ethiopia have not developed meaningful ties with the industry, the entire cost of the internship program relies on government budget. From this budget, students are paid pocket money and universities have covered their associated costs with internship management

Therefore, while considerable amount of effort and resources are being invested since its introduction, the impact of the program on engineering and technology education is not yet evaluated. This has been the driving force for the researchers to take the initiative to conduct a formal assessment to evaluate the impact of the ETEIP in Ethiopia.

\subsection{Research Questions}

The core research questions of the survey study have been:

- What are the major influencing factors of effective internship program implementation?

- What are the key benefits and opportunities of intern hosting organizations as a result of participating in internship programs?

- What is the impact of internship program implementation on the hosting organization?

- What relationships are there between the different factors affecting the internship program in Ethiopia?

\subsection{Purpose of the Study}

The objective of this assessment is to collect the views of employers regarding the impacts of the mandatory ETEIP on the engineering and technology education in Ethiopia so as to learn from the past and improve its future on policy direction at national level. The specific objectives to be addressed in this study are:

- to evaluate the benefits gained by the host organizations involved in the internship program

\footnotetext{
${ }^{1}$ This estimate is based on MoE, Education Statistics Annual Abstract, 2007 E.C. (2014/15) Undergraduate Enrolment in Government institutions by Program.
} 
- to address the feedbacks of involving employers and identify key influencing factors on the intern performances

- to assess the opportunities created as a result of internship program participation

- to propose possible improvement options of the program including potential policy options.

\section{Literature Review}

An internship is a period of training carried out by a student within a company or organization. Basically, the objective of internship program is to expose students to the real world of work and in the process, provide feedback to institutions on the relevance or otherwise of the curriculum (Adebakin 2015). Through internship programs or experiential education settings, students learn by doing within the organization or company. Such an experimental learning assist students to achieve intellectual goals through broad range of academic endeavours, from volunteer activities and services to practicum and internships. Two of the most common forms of experimental learning are the practicum and internship (Simons et al., 2012). The main difference between the two is simply the degree of expected involvement of the student in the real work. While in the case of practicum the participation of the student in performing tasks is to a limited extent, internship involves independent application of skills and knowledge in the workplace setting. Internship is defined by the National Association of Colleges and Employers (NACE) as: "a form of experiential learning that integrates knowledge and theory learned in the classroom with practical application and skills development in a professional setting (RI-University, 2012). It gives students the opportunity to gain valuable applied experience and make connections in professional fields they are considering for career paths; and give employers the opportunity to guide and evaluate talent. Investigation on experimental learning have noted improvements in personal (i.e., discipline related knowledge) and interpersonal (i.e., communication skills) civic (i.e., cultural competence and social responsibility) and professional (i.e., career interests) development among undergraduate students (Simons et al., 2012). According to (Brown, 2010), internships offer carefully planned and monitored work experience with the goal being to gain practical skills from on the job exposure. Students in technical disciplines, when questioned, mention benefits such as obtaining real-world experience, learning more about a company, applying theoretical and analytical knowledge acquired in class, networking, and gaining hands-on experience (Clements \& Cord, 2013).

The benefits of internships in engineering and technology fields are recognized by leaders in the discipline, business and industry representatives, and students. Literatures show that internships have been described by industry leaders as "a critical tool" to help prepare graduates to successfully enter the workplace (Clements \& Cord, 2013). Among the different benefits mentioned by different scholars include promote academic, career and/or personal development, balance the intern's learning goals with the organization's needs, enhance work place related and soft skill development, and allow students to get the opportunity to apply their knowledge and skills in a professional setting while still in school. 
The major stakeholders in internship program are Industry, Educational Institutes, Students, Mentors/Supervisors, Government and NGO's (Mgaya \& Mbekomize, 2014; Ndibuuza, 2016). An internship providing company can be offered by any type of organization, large or small, for-profit or not-for-profit, and within any industry or economic sector (Haddara \& Skanes, 2007).

It has been more than 100 years since internship in engineering program began to be implemented in United States of America. The program faces lots of resistances both from traditional educators and uncommitted industrialists; however, this program expanded very quickly and proved to be successful. Moreover, the trend is used as a model in educational institutes in different disciplines (Haddara \& Skanes, 2007).

International educational program like Pacific Rim Experiences for Undergraduate Program (Prime) and German Academic Exchange Service (DAAD), focus on research based internships where interns are employed from abroad countries to work with researchers and professors in hosting country. The key motivator for this kind of program is the demand of workforce that works collaboratively across cultures and disciplines to address major global challenges (Arzberger et al., 2010; Institute of International Education, 2009). In Australia, for example, host organizations are more involved in internships management and selection of students to undergo industrial attachment (Mgaya \& Mbekomize, 2014). However this is not the case in Ethiopia, because the facilitation and management mostly relied on University-Industry linkage unit at the universities. In Ethiopia internship/externship is considered as a link between university and industry. As referred in MOST (2013) the university industry linkage is necessary to let students, academic staffs, and TVET trainers gain practical learning opportunities in industries. Even if engineering and TVET students are allowed to be engaged in practical learning in industries, the outcome is not as expected when it is referred to student-to- mentor and student-to supervisor ratio (MOST, 2013). There exists also a major variation among the different higher education institutions in the implementation of the mandatory internship program in terms of prior preparation, placement, supervision and evaluation. Whereas the implementation of internship programs in Ethiopia is a recent phenomenon, its role particularly on the enhancement of technology and engineering education is believed to be vital. With this end the countries science, technology and innovation policy indicated internship programs as one means of integrating universities with local and international organizations.

\section{Methodology}

This impact assessment survey begins with the selection and formulation of survey questions and ensuing design of range of techniques to be used to evaluate the extent to which the current internship program on engineering and technology education quality throughout the country. These techniques include descriptive a nation-wide survey of representative sectors from all kinds industries, nearly all higher level institutions running engineering and technology education programs, as well as other stakeholders involving in the higher education subsector. Furthermore, the survey is designed in such a way that it permits to identify range of factors that influence the way the internship program has been 
administered. In order to address the above objectives, a representative sample throughout Ethiopia was taken from all sizes and sectors of the industry. The samples were stratified by regions, industry size and sector. Participants of the survey were recruited based purposive sampling techniques for the sake of obtaining reliable information from the sample population. Moreover, recently returned interns, recently employed graduates, in-company supervisors, academic mentors from the universities and university officials were included in the survey.

Due to its multidisciplinary nature and diversification of target groups, this survey uses a combination of qualitative and quantitative approaches. While the quantitative approach involves the generation of data in a form that can be subjected to rigorous quantitative analysis including associations and multivariate analysis, the qualitative approach is concerned with the subjective assessment of attitudes, opinions and expectations. More specifically, descriptive methods of the quantitative approach are used to form a database from which to infer characteristics or relationships of population.

This usually means survey research, where a sample of a population is studied (questioned or observed) to determine its characteristics, and it is then inferred that the population has the same characteristics. In the qualitative method, the technique of focus group and depth interviews were used. Focus group is a type of in-depth interview accomplished in a group, whose meetings present characteristics defined with respect to the proposal, size, composition, and interview procedures (Freitas et.al 1998). While this survey employs a flexible design that provides opportunities for considering many different aspects of the situation, an accurate description of a situation or of an association between variables is also sought, where appropriate, to minimize bias and maximize the reliability of the data as collected and analyzed.

\subsection{Sample Size Determination}

Generally, the sample size for any study depends on the following major points namely: acceptable level of significance or confidence interval, population standard deviation, and margin of error. This is the level of tolerance where the sample mean may deviate from the population mean.

In this survey study, the acceptance level considered was 5\% significant level. Based on this acceptance level, the sample size was determined using the equivalent $n=\frac{z^{2} \delta^{2}}{E^{2}}$, where $\mathrm{z}$ is the critical region, $\delta$ is the population standard deviation; $\mathrm{E}$ is the error percentage or margin of error. Based on this equation, with 5\% significant level or $95 \%$ confidence interval, the value of the $\mathrm{z}=1.96$, the population standard deviation is $\delta=1$. The margin of error which is a measure of how much the sample mean deviates from the population. Since the sample and population mean is not known, 20\% error percentage tolerance of the sample mean from the expected population was assumed. 
Based on this assumption the sample size was determined as $n=\frac{1.96^{2} 1^{2}}{0.2^{2}}=97$. While based on preliminary assessment made in the Ethiopian industries for the purpose of sampling and its framework, the study was planned to incorporate a total of 110 industries to be included in the survey, in the actual survey however, 103 different sector industries including the manufacturing, processing, service, construction, ICT, mining and others were involved.

The balance among the different sectors of the industries was kept to enable us accommodate all kinds of engineering and technology disciplines. Figure 1. shows, the proportion of industrial sectors participated in the survey.

A total sample of $n=2719$ individual, of whom 2163 current internship returned students, 273 academic mentors who have participated on mentoring students were randomly selected from 23 universities in engineering and technology disciplines. Moreover, from the 103 industries, a total of 101 recently employed engineering and technology graduates and 182 company supervisors were included in the survey. Furthermore, site visits and focus group discussions with major stakeholders of the program were administered to validate the findings of the quantitative analysis and further discuss on potential recommendations for further action.

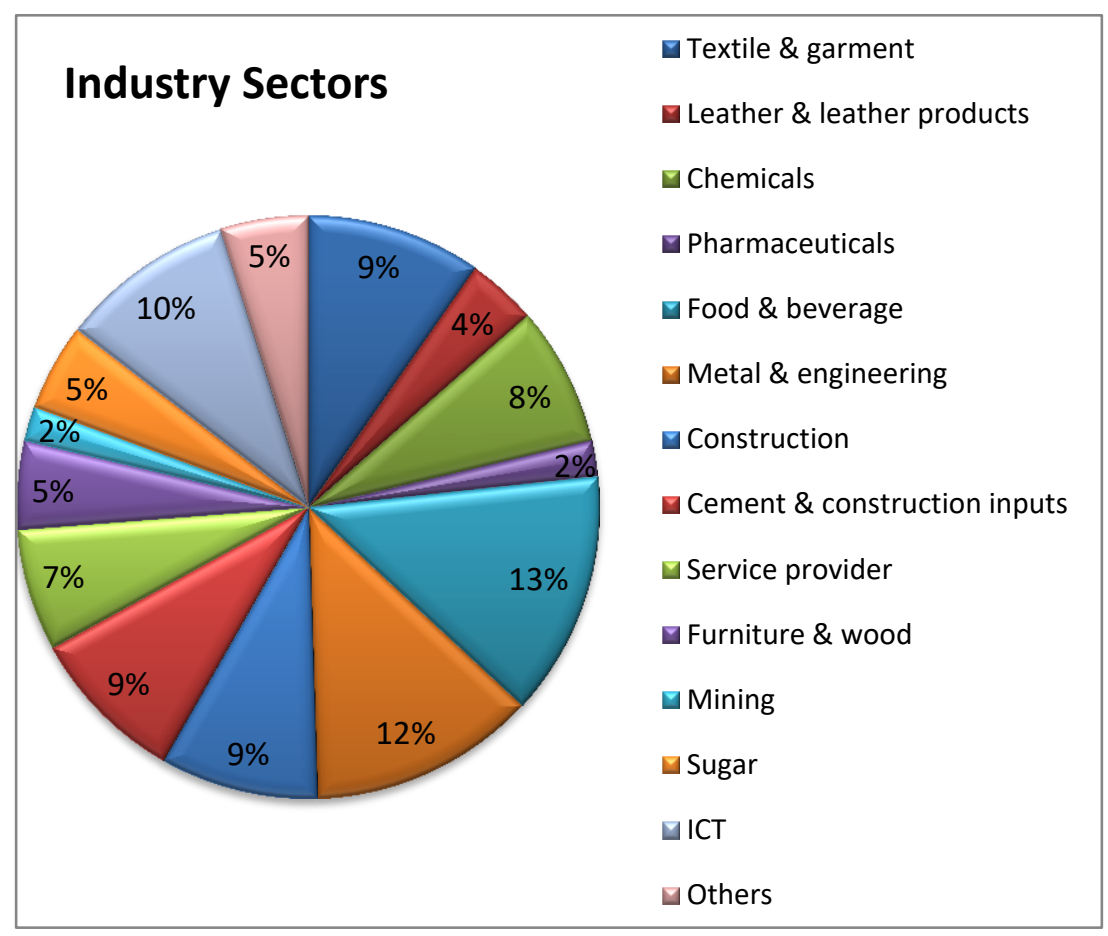

Figure 1. Distribution of industry sectors

\subsection{Method of Data Collection}

Various techniques are used to evaluate the impact of present internship programs in Ethiopian Engineering and Technology Education. These techniques include both primary 
and secondary data collection techniques and instruments. With regard to primary data, a standard survey questionnaire was used to collect information and data from respondents. The validity and reliability of the tools were pretested using test retest methods, expert panels and Crobach's alpha coefficient. Due to the possibility that previous students cannot be contacted and the well-known fact that online surveys have a lower response rate than other modes of surveys, the study uses self-completion of paper questionnaire delivered by trained research assistances.

The assessment was started by geographically clustering the industries and universities across Ethiopia. A total of seven clusters were established to systematically to manage the data collection and compilation activities. As a result, seven university-university industry linkage officers were involved in the seven clusters to collect the data.

Part of the questionnaire was used to collect some demographic data and views of host organizations on how the administration of the internship program could be conducted as well as views on their willingness to continue accepting interns. The rest of the questionnaires were used to collect respondents' views on the prior preparation of students, university and hosting organizations for the program, the learning outcomes of the program and benefits that host organizations acquired from the internship program. Moreover, their views on the students' attitude towards the program, the impact of the internship program on employability, entrepreneurial orientation and overall quality of engineering/technology education were addressed.

\subsection{Evaluation of the Scientific Instruments}

Before starting the main data collection, it was necessary to first evaluate the reliability and validity of the instruments. As a result the standard questionnaire developed was exposed for pilot validity test before the final version was printed and distributed. The main reasons for the pilot testing of the survey questionnaire were the following:-

1) To measure the validity of the scientific instruments - or in other words to check whether the questionnaire can measure what it intended to measure;

2) To check whether the scientific questionnaire represented the content of the intended survey anticipated results;

3) To prove that the questions were appropriate for the sample population;

4) To check if the questionnaire was comprehensive enough to collect all the information needed to address the purpose and goals of the study.

While there are different methods of pretesting data collection tools employed, a choice had to be made, based on the availability of time, associated costs, and the reliability of the different methods. Therefore, a combination of reliability and validity tests were used. Reliability based on internal consistency was measured by calculating a statistic known as Crobach's coefficient alpha. Hence to check the reliability of the designed questionnaire sample tests were made on the questionnaire by taking randomly selected respondents from Addis Ababa Institute of Technology (AAiT) and Bahir Dar Institute of Technology (BiT) 
students. The resulting Chrombach's alpha coefficient (0.78) indicates that the reliability of the data collection questionnaire is appropriate to get data that will enable to generalize about the entire population.

Moreover, validity tests (expert review) were also used. The data collection questionnaire which was developed by the lead consultants was reviewed in a kick-off workshop arranged with university industry linkage experts to introduce the tools and strategies of the data collection. This expert panel was formed with a small group of individuals (10 professionals experienced in internship administration and university industry partnership), invited to critique the questionnaire from multiple perspectives. In a group session, the panel reviewed the questionnaire question by question. The core final results and recommendations of the review were incorporated. Moreover, the views of different stakeholders were incorporated to amend the questionnaire and the final version was sent to the assistant researchers for collecting and compiling the raw data.

With regard to secondary data, mainly electronic sources were used to get data on number of engineering and technology discipline graduates from different universities. Moreover, various assumptions, estimations were made based on available facts particularly to estimate the cost of internship program incurred by government.

Moreover, analysis and evaluative methods including standard statistical packages (SPSS) were used to show the descriptive results and to examine any cross-tabulation, or associations (correlation and regression analysis) or grouping which emerges (through factor analysis) for the quantitative data. To assist further investigation of the case local and international benchmarking programs were arranged before formulating the final results of the survey.

\section{Results and Discussions}

\subsection{Company/ Industry Preparation}

Preparation of the host organization prior to the start of the internship program plays an important role in keeping the quality of the program to the expected level. Different literature witnessed that the effectiveness of any internship program is largely depend on the capacity of industry to supervise students, commitment in the follow up and provision of necessary facilities in favour of the program. Preparedness of the hosting organizations were assessed using attributes like readiness to orient students up on arrival to their companies, the capacity to accommodate students for relevant work assignment, the capacity to supervise students, knowing its role in hosting the intern, and its commitment to follow up students during the entire period of the internship program.

The results of the survey reveal that hosting organizations are well aware about the expectations of the program. While the capacity of each industry may vary, the survey results show that most hosting companies were found to be prepared in terms of provision of adequate professional supervision, relevant work assignment and follow up. This is evidenced by the facts that over $80 \%$ of the respondents believe that companies have the capacity to supervise the student's day to day activities. 
On the other hand, there is a general argument among industry owners that the timing of internship may not sometimes coincide with the actual operational period of the industry. For example, operational time is found to be critical in construction sectors because most of them are engaged in temporary projects. In other words, the project might end in between the internship program which enforces students to be engaged in another project sites which in return affect their experience in the program.

\subsection{Organizational Environment}

The hosting organization of an internship program is probably the single most important influence on an intern's impression of the entire program, and thus the chances that the effectiveness of the program depends. As varied as organizations are in size, age, industry and product or service, so are their internship activities. Thus, addressing organizational environments from both the industry and the university side is crucial. This is because hosting an internship program takes planning and coming to consensus on program goals that can be understood by all involved.

Interns were asked if they were given proper and meaningful orientation about the organization's purpose, services, clientele, and operating practices by the hosting organization prior to their engagement at the real work environment. Survey results indicate that only $54 \%$ of respondents agree on the provision of appropriate orientation before starting the internship program and $57 \%$ of the same respondents' replay that there is provision of feedback on input and work performed.

Another area of concern studied was whether the hosting organization/company provided the intern student a planned, supervised program of career related experiences in terms of scheduled supervision and designating an area expert to serve as the site supervisor and made available space, supplies, and other resources needed for completing assignments.

Survey results have also shown that many students start their internship unfamiliar with the activities, environment, and objectives of business and industry. Even though interns may have given with work assignments in the industry in particular departments, these experiences may not have exposed them to organizational policies, the need for confidentiality, the importance of teamwork, or the profit-making orientation of business.

A study conducted by (Simons et al., 2012) states that, employers who take adequate time at the beginning of the internship to orient the student reap productivity and effectiveness more quickly than those who don't. While providing the interns with a variety of tasks by accommodating the needs of the organization is the anticipated role of the hosting organizations, actual results prove the opposite. As part of the educational process, internship work activities should focus on projects specifically related to the academic major and the degree the interns expect to receive. There is a general view among scholars that engaging interns in industries by itself cannot result in expected outcomes but rather a waste of resources and time unless supported with appropriate follow up and continuous supervision. 


\subsection{Impact of Internship Program in the Industry}

One of the major areas of interest in this survey was to know the views of hosting companies about what impact has the program has brought for their respective organizations. From the perspective of the companies, it has been found that an internship must offer them a return and not just be done only for the benefit of the student. To this end, internship value was measured through the degree to which employers' perceived the internship experience as a means to provide the organization with respect to using interns as flexible and cost-effective work force and considering them as potential employees and train them accordingly.

Using six 5-point Likert scale items designed to assess the employer's perception, $82 \%$ of employers believe the program has increased their image in the community by contributing its expertise to educational institutes as a form of experiential learning platform. Whereas $80 \%$ of the employers consider interns as potential employees and train them accordingly, $71 \%$ of them also use interns as flexible and cost-effective work force.

\subsection{Multivariate Analysis}

An advanced statistical analysis using multivariate approach was also conducted to see the relationship and impact of internship on the technology and engineering education in Ethiopia. The variables/constructs are clearly shown on each of the graphs below. The reliability of these constructs is tested and all of them have got a Chronboch alpha value more than 0.80 indicating good reliability of the variables. Moreover, during the regression analysis, multi- collinearity test was also conducted and the Variance Inflation Factors (VIF) of the model run was less than harmful level.

The results of correlation matrix based on industry response presented in Table 1. indicates that all the constructs have strong and statistically significant correlation with each other with p-value less than 0.01. It is observed that though the assessment factors (AF) has a strong and statistical significant correlation with organizational impact (OIM), but the regression analysis indicated that the assessment factors (AF) are not a good indicators to the impact of internship on industries performance (std. beta value -0.065 and $p$-value $=0.745$ ). In this model except AF, all the remaining variables, student preparation (SP) and interns' commitment(IC) were good predictor of OIM.

Table 1.Correlational matrix based on industry response

\begin{tabular}{|l|l|l|l|l|}
\hline & SP & IC & AF & IITEE \\
\hline IC & $.619^{* *}$ & & & \\
\hline AF & $.638^{* *}$ & $.955^{* *}$ & & \\
\hline OIM & $.528^{* *}$ & $.699^{* *}$ & $.670^{* *}$ & \\
\hline IITEE & $.582^{* *}$ & $.588^{* *}$ & $.598^{* *}$ & $.597^{* *}$ \\
\hline \multirow{2}{*}{$* *$ Correlation is significant at the 0.01 level (2-tailed). } \\
\hline
\end{tabular}




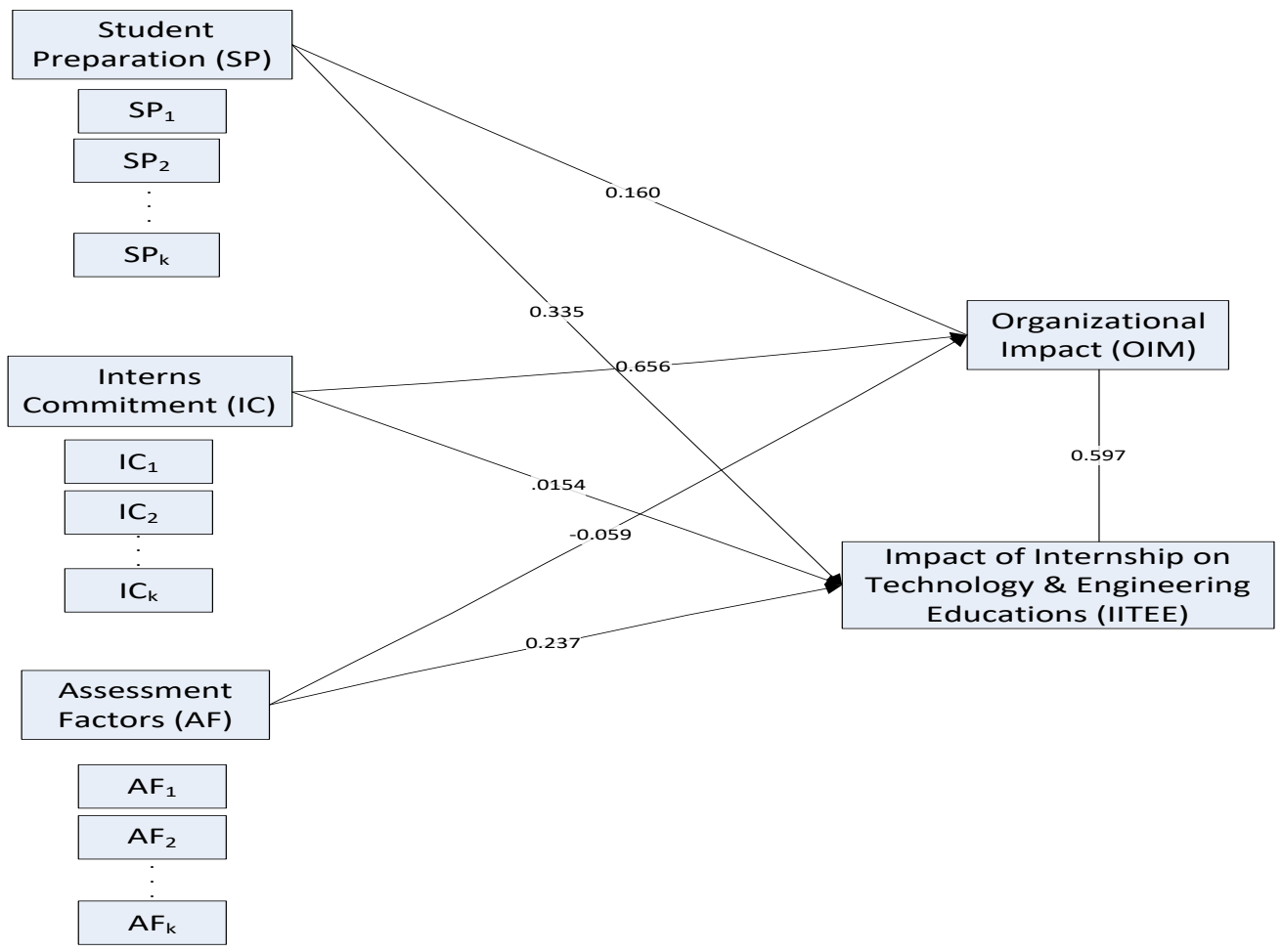

Figure 2. Research model on industries perspective

Table 2.The result of structural equation model on the industries perspective

\begin{tabular}{|c|c|c|c|c|c|c|}
\hline \multicolumn{2}{|c|}{ Path } & Std. Beta & Sig. & DF & Adj. R2 & Model \\
\hline$\beta_{11}$ & $\mathrm{OIM}<==\mathrm{SP}$ & 0.215 & 0.021 & \multirow{3}{*}{3.000} & \multirow{3}{*}{$0.503(\mathrm{OIM})$} & \multirow{3}{*}{0.000} \\
\hline$\beta_{12}$ & OIM <==IC & 0.736 & 0.000 & & & \\
\hline$\beta_{13}$ & $\mathrm{OIM}<==\mathrm{AF}$ & -0.065 & 0.745 & & & \\
\hline$\gamma_{11}$ & IITEE <==SP & 0.446 & 0.000 & \multirow{3}{*}{3.000} & \multirow{3}{*}{ 0.427(IITEE) } & \multirow{3}{*}{0.000} \\
\hline$\gamma_{12}$ & IITEE <==IC & 0.171 & 0.423 & & & \\
\hline$\gamma_{13}$ & IITEE <==AF & 0.259 & 0.227 & & & \\
\hline$\theta_{11}$ & IITEE <== OIM & 0.592 & 0.000 & 1.000 & 0.357 (IITEE) & 0.000 \\
\hline
\end{tabular}

When the direct impact of SP, IC and AF are evaluated against IITEE, except SP all the remaining constructs are not a good predictor on the quality of engineering education. With the industries perspective without good student preparation (SP), having a good intern commitment (IC) and other potential assessment factors (AF) it would be impractical to bring impact using internship on technology and engineering educations (Figure 2 and Table 2). On the final run, the result shows that when the Organizational Impact (OIM) of internship is good, the impact of internship on technology and engineering education (IITEE) ( $p$-value $=0.000$ ) will be better. Moreover, the path leading from IC to OIM and from OIM to 
IITEE are the longest among all the other constructors. This indicated that for industries, internes commitment (IC) is a good predictor for their industries to benefit from the internship program. Subsequently when the organizations got a positive impact on the internship program (OIM), the impact of internship on quality of technology and engineering will be the better predictor for them.

\section{Conclusion}

This study provides an empirical investigation of the impacts of internships internship program in Ethiopia with respect to students' academic achievements, industry benefits and graduate career developments. While the sample was representative of undergraduate engineering/technology majors it was drawn from all universities and all sectors of industries in Ethiopia. Therefore the findings can represent the nationwide picture of the situation.

Whereas the prime objective of the internship program is to benefit the students, the findings of this survey showed that host organizations could benefit from the knowledge that students transfer from their university experiences. However, the finding in this survey doesn't show strong support as a considerable portion of employers (26\%) were undecided about the importance of internship program for their organization. Moreover, the degree to which intern performance influences employer perceptions of the value of the internship program is found to be low. This is evidenced by the fact that there has been less likelihood to show preference in hiring high performing interns over non-interns and very limited practice and willing to pay compensation for interns during their stay in the organizations.

Generally, despite its flaws in implementation and administration, internship programs in Ethiopia have an important part in the academic curriculum. It plays a crucial role of helping undergraduate students to make the connections between their traditional coursework and the workplace. Apart from its impact on the academic and practical education it also provides students with a keen insight into work and research culture. Additionally the impact of internship on the interpersonal skills of undergraduate students is highly appreciated by the findings of the survey.

\section{Acknowledgment}

The authors would like to acknowledge the Sustainable Training and Education Program (STEP) of GIZ and the Bahir Dar Institute of Technology at Bahir Dar University for their joint sponsorship to conduct the survey study.

\section{References}

Abu, B. M., Harun, R., Yusof, K., \& Tahir, I. (2011). Business and accounting students' perceptions on industrial internship program. Journal of Education and Vocational Research, 1(3), 72-79.

Arzberger, P., Wienhausen, G., Abramson, D., Galvin, J., Date, S., Lin, F.-P., . . Shimojo, S. (2010). PRIME: An Integrated and Sustainable Undergraduate International Research Program. Advances in Engineering Education, 2(2), n2. 
Brown, N. (2010). WIL [ling] to share: an institutional conversation to guide policy and practice in work-integrated learning. Higher Education Research \& Development, 29(5), 507-518.

Clements, M. D., \& Cord, B. A. (2013). Assessment guiding learning: developing graduate qualities in an experiential learning programme. Assessment \& Evaluation in Higher Education, 38(1), 114-124.

Haddara, M., \& Skanes, H. (2007). A reflection on cooperative education: From experience to experiential learning. Asia-Pacific Journal of Cooperative Education, 8(1), 67-76.

Institute of International Education, I. (2009). Evaluating the DAAD's Research Internships in Science and Engineering (RISE) Program. Retrieved from

Mgaya, K., \& Mbekomize, C. (2014). Benefits to Host Organizations from Participating in Internship Programs in Botswana. Asia-Pacific Journal of Cooperative Education, 15(2), 129-144.

MOST. (2013). Procedural Directive for Linking of Education and Training, Research Institution and Industries. Addis Ababa: FDRE: Ministry of Science and Technology.

Ndibuuza, F. (2016). Effectiveness of Internship in Fostering Learning: The Case of African Rural University. Psychology, 6(1), 32-41.

RI-University. (2012). Employer Guide to Structuring a Successful Internship Program.

Simons, L., Fehr, L., Blank, N., Connell, H., Georganas, D., Fernandez, D., \& Peterson, V. (2012). Lessons Learned from Experiential Learning: What Do Students Learn from a Practicum/Internship? International Journal of Teaching and Learning in Higher Education, 24(3), 325-334.

\section{Copyright Disclaimer}

Copyright reserved by the author(s).

This article is an open-access article distributed under the terms and conditions of the Creative Commons Attribution license (http://creativecommons.org/licenses/by/3.0/). 